\title{
Neurophenomenology of Out-of-Body Experiences Induced by Hypnotic Suggestions
}

This is a copy of the accepted manuscript published by Taylor \& Francis Group in the International Journal of Clinical and Experimental Hypnosis, 67(1): 1-30, 2019

Copyright (C) International Journal of Clinical and Experimental Hypnosis

ISSN: 0020-7144 print / 1744-5183 online

DOI: https://doi.org/10.1080/00207144.2019.1553762.

Enrico Facco ${ }^{1,2,3}$, Edoardo Casiglia ${ }^{4}$, Benedikt Emanuel Al Khafaji ${ }^{5}$, Francesco Finatti ${ }^{4}$, Gian Marco Duma $^{6}$, Giovanni Mento ${ }^{5}$, Luciano Pederzoli ${ }^{7}$ and Patrizio Tressoldi ${ }^{3,5}$

${ }^{1}$ Studium Patavinum - Department of Neurosciences, University of Padua, Italy;

${ }^{2}$ Inst. Franco Granone - Italian Center of Clinical and Experimental Hypnosis (CIIICS), Turin, Italy ${ }^{3}$ Science of Consciousness Research Group - Department of General Psychology, University of Padua, Italy.

${ }^{4}$ Studium Patavinum - Department of Medicine, University of Padua, Italy

${ }^{5}$ Department of General Psychology, University of Padua, Italy;

${ }^{6}$ Department of Developmental and Social Psychology, University of Padua, Italy;

${ }^{7}$ EvanLab, Florence, Italy;

Correspondence concerning this article should be addressed to Enrico Facco, Department of Neurosciences, Chair of Dental Anesthesia, University of Padua, Via Giustiniani 2, 35128 Padua, Italy; Phone +39 0498212040; Email: enrico.facco@ unipd.it

Funding: None 


\begin{abstract}
Inducing out-of-body experiences in hypnosis (H-OBEs) offers an almost unique opportunity to investigate them in a controlled condition.

OBEs were induced as in imaginative task in a resting condition (I-OBE) or in hypnosis (H-OBE) in a group of fifteen high hypnotizable subjects. A 32-channel EEG was recorded and the spectral power and imaginary coherence of each frequency band and each couple of electrodes were calculated. At the end of each session, the Phenomenology of Consciousness Inventory (PCI) was administered to check the phenomenological aspects of their experience.

Significantly higher scores in the Altered State, Positive Affect, Altered Experience and Attention subdimensions of the PCI were reported in H-OBE than in I-OBE, which were associated with a significant decrease of power in beta and gamma band activity in right parieto-temporal derivations. Our results suggest that the H-OBE may offer a useful experimental model of spontaneous OBEs.
\end{abstract}

Keywords: Out-of-Body Experience; Hypnosis; Consciousness; EEG; Phenomenology, Near-Death Experiences 
Near-Death Experiences (NDEs) and Out-of-Body Experiences (OBEs) are intriguing phenomena, which have fascinated the humanity across recorded time, from the myth of Er in the Plato's Republic - the soldier who, thought dead, travelled through the Hades, saw and then witnessed the process of reincarnation - to the Jack London's fiction The Star Rover (London, 1915). London, who defined himself as a fervent materialist monist, narrated the memories of previous lives and the OBEs of Darrell Standing, a prisoner sentenced to death, bound in a straitjacket in an isolation cell of St. Quentin. In this long-lasting condition, which London defined as a sort of living dead, he could exit from his physical body and travel with his mind, also visiting Jake Oppenheimer (a prisoner executed in 1913) in another cell of St. Quentin. What is intriguing, is that London drew his fiction from the testimony of real St. Quentin's prisoners, Jake Oppenheimer and Ed Morrell, the latter reporting the OBEs. It is also noteworthy that in the fiction the main character's experiences led him to keep his mental health and promote resilience, enduring jail and tortures and facing his execution in full bliss and self-control. This is in line with the transformative power of NDEs (e.g., overcoming the fear of death) disclosed by the scientific studies published some 80 years later (Greyson, 2014; Bruce Greyson, 2003; van Lommel, 2011).

NDEs and OBEs - as well as all subjective phenomena, including consciousness itself - have been disregarded or misunderstood, due to their ostensible incompatibility with the ruling reductive physicalist stance until the latter $20^{\text {th }}$ century (Facco \& Fracas, 2018; Facco, Agrillo, \& Greyson, 2015; Facco, Lucangeli, \& Tressoldi, 2017). Therefore, they were mainly considered as plain, meaningless by-products of organic or functional brain disorders leading to a multisensory disintegration and, clinically, only a matter of diagnosis and/or pharmacological manipulation (Blanke, Landis, Spinelli, \& Seeck, 2004). On the other hand, the studies reporting seizures as a cause of OBEs (Britton \& Bootzin, 2004; Bünning \& Blanke, 2005) have been later disproved by the absence of a clear relationship between the two (Greyson, 2014). In fact, the relationship between NDEs, OBEs and seizures is a conjecture without evidence for the following reasons: a) they are not part of the symptomatology of epilepsy (Rodin, 1989); b) in a study by Greyson et al. (2014) $7 \%$ of patients with seizures reported OBEs, but they occurred only once or twice in their life and could not be associated to epilepsy, EEG and/or medications. OBEs have also been recognized to be phenomenologically and neurophysiologically different from autoscopies and heautoscopies (see Brugger, Regard, \& Landis, 1997; Lopez et al. 2008). Thus, OBEs are neither related to seizures nor psychiatric disorders and cannot be considered as their plain by-product - i.e., out-of-body does not necessarily mean "out-of-mind” (Agrillo, 2011; Greyson, 2000). 
OBEs may also occur in up to $26 \%$ of the non-clinical population, challenging reductionist interpretations of OBEs in terms of brain damage, though they may still be neuropsychologically interpreted as the result of right parieto-temporal dysfunction leading to a disruption of multisensory integration (Braithwaite, Samson, Apperly, Broglia, \& Hulleman, 2011). In short, the nature of OBEs remains unclear, suggesting the need for further study of their neurophenomenology and their possible cognitive and metacognitive implications.

Both NDEs and OBEs belong to the field of Non-Ordinary Mental Expressions (NOMEs), a topic including other intentionally-achieved or spontaneously-occurring uncommon experiences, like hypnosis, meditation and mystical experiences (Cardeña \& Facco, 2015; Facco et al., 2015), different phenomena sharing some interesting links and common aspects (Facco, 2017, 2018; Greyson, 2014). The noun non-ordinary emphasizes their non-pathological nature and their peculiarity with respect to usual ordinary consciousness activities, a fact in turn emphasizing the socio-cultural, epistemological and, perhaps, inadvertently prejudicial implications of their previous definition as altered states of consciousness.

Unlike artificially induced full-body illusions (Altschuler \& Ramachandran, 2007; Ehrsson, 2007; Blanke \& Metzinger, 2009; Bourdin et al., 2017), spontaneous OBEs are difficult to investigate given their unpredictability. In fact, they may occur within NDEs - i.e., following severe injuries, like cardiac arrest, head trauma, etc. (Charland-Verville et al., 2014; Parnia et al. 2014; van Lommel, 2011) - or non-traumatic events - e.g. deep meditation, strong emotions, etc. (Cardeña \& Alvarado, 2014). Two previous pilot studies (Pederzoli et al., 2016; Tressoldi et al., 2014, 2015) have shown the possibility of inducing OBEs by specific hypnotic suggestions, thereby making it possible to prospectively explore their phenomenological features and their electroencephalographic (EEG) correlates under controlled conditions.

A recent phenomenological comparison among OBEs experienced within NDEs, spontaneous nontraumatic OBEs and those induced by hypnosis (H-OBE) (De Foe, Al Khafaji, Pederzoli, Prati, \& Tressoldi, 2017) has shown several similarities; they included an increased awareness associated with positive emotions (e.g., "It was as if suddenly I knew everything that was being communicated. It was incredible, beyond words"), a loss of the feeling of time, (e.g., "The concept of time wasn't at all present") and a sensation of having no physical confinements, unlike being in a physical body (e.g., "I feel totally free; I do not perceive boundaries or shapes"). These reported similarities between NDEs, spontaneous OBEs and H-OBE show some common aspects with mystic experiences (Chen et al., 2011) as well as the experiences reported by highly but not low hypnotizable subjects during 
neutral hypnosis (Cardeña, Jönsson, Terhune, \& Marcusson-Clavertz, 2013). As a whole, they suggest a link between all of these different NOMEs, reflecting the still ill-known meaning of the inner, non-pathological and still mysterious activities of human mind, including their metacognitive value and transformational power.

Thus, the OBE phenomenology is very rich from the subjective first-person perspective (1PP) and suggestive of a real experience of detachment of the Self from its physical body, associated to the perceived ability to expand one's cognitive capacities beyond the space and time constraints imposed by brain and body. On the other hand, a few, very uncommon cases of patients witnessing what happened in the emergency room while they were out-of-body during cardiac arrest appear unbelievable and challenge our knowledge of both consciousness and the pathophysiology of brain anoxia (Parnia et al., 2014; Sabom, 1998; van Lommel et al., 2001). Nevertheless, they are observed facts and, as such, call for a scientific interpretation, while integrating the 1PP and 3PP may help investigating their phenomenology beyond the limits of the reductionist approach only aiming to disclose brain mechanisms of these complex and intriguing experiences.

The aim of this study was the comparison between the neurophenomenology of the H-OBEs and those imagined when in state of ordinary consciousness (I-OBE) in subjects without any previous experience of spontaneous OBEs. As a main working hypothesis, we proposed that an overlapping of the functional underpinnings of these two phenomenological states would support the view that these experiences are a by-product of participants' mental imagery. On the other hand, the presence of clear neurophenomenological differences between H-OBEs and I-OBEs would provide new information on their nature, as well as on the physiology of consciousness, selfhood and the capacity of dissociation between 1PP and the physical body. In other words, H-OBEs might result to be phenomenologically different from I-OBE as well as by OBE illusions elicited by physical stimulation, and show common elements with spontaneous OBEs occurring both in non clinical conditions and in NDEs; if this is the case, H-OBE - which may be experimentally induced and, thus, reproducible -, might be a good model of spontaneous OBEs.

The Minimal Phenomenal Selfhood (MPS) perspective has been defined by Blanke \& Metzinger (2009) as "a phenomenal property, namely the conscious experience of being a self. It is the experience of being a distinct, holistic entity capable of global self-control and attention, possessing a body and a location in space and time". Instead, in OBEs one can express a MPS without a physical body, as well as the possibility of moving around in space and time without constraints, often with a 
perceived enhancement of consciousness, global self-control and attention, the nature and mechanisms of which are still unclear.

Several efforts have been dedicated to identify the neural correlates of hypnosis by neuroimaging techniques, EEG and Event Related Potentials (ERP) and an increasing number of studies has been published in the past two decades. There is now evidence that hypnosis yields intentional and complex changes in brain areas and circuits; for example, relaxation and absorption lead to the activation of the anterior cingulate cortex (ACC) somatosensory and motor cortex as well as a decreased perfusion of temporal lobes (Rainville et al., 1999b; Rainville et al., 2002; Rainville \& Price, 2003). Relaxation is also paralleled by increased perfusion of occipital cortex and decreased perfusion in the brainstem, cerebellum, thalamus and basal ganglia and prefrontal cortex, while absorption is paralleled by increased perfusion of brainstem, prefrontal cortex and decreased occipital perfusion. Furthermore, hypnosis has been reported to affect the activity of the default modality network (McGeown et al., 2009; Deeley et al., 2012), likewise meditation (Taylor et al., 2013; Brewer et al., 2011; Jang et al., 2011; Pagnoni et al., 2008). It is worth emphasizing that the anterior cingulate cortex is a crucial area in pain perception, monitoring of conflict between incongruent stimuli, arousal, attention, cognition, emotion, motivation and movement control (Muller et al., 2012; Mak et al., 2009; Vincent et al., 2008; Faymonville et al., 2006; Egner et al., 2005; Raz et al., 2005; Frith, 2002; Casiglia et al., 2010). Hypnotic suggestions to induce an experience of pain, unlike imagined pain in resting conditions, strongly affect both the activation and the connectivity of brain areas belonging to the pain neuromatrix. Instead, hypnotic suggestions of analgesia allow for a significant increase in pain threshold, up to the level of surgical anesthesia (Derbyshire et al., 2004; Facco et al., 2011; Facco et al., 2013; Facco, 2016; Faymonville et al., 2000, 2003; Hofbauer et al., 2001; Rainville \& Price, 2003; Rainville et al., 1999a; Rainville et al., 2002; Roder et al., 2007; Vanhaudenhuyse et al., 2014).

Despite clear evidence that hypnosis may yield specific brain changes, these results are dyshomogeneous, because hypnosis is far from being a single monomorphic activity and the wide range of patterns of activation and deactivation depend on both hypnotic tasks and subject's hypnotic ability, making the interpretation of results a hard job. This is especially true when the EEG is used, given its high variability and the problems related to the solution of the so-called inverse problem. Despite these limitations, the EEG remains a valuable tool, given its high temporal resolution and, thus, the capacity to track ongoing brain activity changes from induction through the post-hypnotic phase, as well as their distribution on the scalp.

\section{Methods}




\section{Participants.}

Fifteen adult healthy volunteers, 10 females and 5 males (age range: 21 - 59; mean: 28; $\mathrm{SD}=10.02$ ) were included in the study. They were recruited among the pool of highly hypnotizable subjects known by the authors. Their number was predefined by a statistical power analysis related to a paired t-test with an estimated effect size of 1 , alpha $=.05$ and statistical power $=.95$, computed by using the software G-Power (Faul, Erdfelder, Lang, \& Buchner, 2007). The estimated effect size derived from the pilot study of Pederzoli et al (2016). The preregistration of the study is available here: https://osf.io/9x65m/register/565fb3678c5e4a66b5582f67

The inclusion criteria were the following: a) absence of any medical and psychiatric condition and use of any psychotropic drug; b) high hypnotizability, defined by an induction score of 7.5 or more, according to the 0-10 point scale of the Hypnotic Induction Profile (HIP) (Spiegel, 1977; Spiegel \& Spiegel, 2004); c) a strong motivation toward this study; d), no signs of worry or fear when reckoning to undergo an OBE.

The participants were reimbursed $€ 10$ for their participation in each of the two sessions. The study was approved by the Ethics Committee of the School of Psychology of the University of Padua (id. protocol 2058) and was conducted according to the principles of the Declaration of Helsinki for Human Research. Each participant was previously and individually informed in an appropriate place about the purpose and methods of the procedure and were free to ask all questions for a full comprehension of the procedure. All participants gave their informed consent.

\section{Procedure}

In the first session, participants were first informally interviewed by the last author (PT) regarding their knowledge of OBEs and the sources of their information and were requested to sign in the informed consent. Then, their hypnotizability was assessed by the first author (EF). Highly hypnotizable subjects were randomly assigned to the first experimental session (I-OBE or H-OBE session, as described below); the second session was performed at least a week later.

At the end of the first session, participants were requested to fill in the Italian version of the

Dissociative Experience Scale (DES) (Carlson \& Putnam, 1993) and the Cardiff Anomalous Perceptions Scale (CAPS) (Bell, Halligan, \& Ellis, 2006) for assessment of excluding clinical conditions. At the end of each of the two experimental sessions, they were also requested to fill in the Phenomenology of Consciousness Inventory (PCI) to check their phenomenological experience of the just completed H-OBE or I-OBE session. The PCI - including 53 questions requiring answers 
based on a 7-point Likert scale - has shown a good psychometric reliability and validity and has been widely used to check cognitive and emotional aspects of different non-ordinary states of consciousness (Pekala, 2013, ch. 5 and 6; Pekala et al. 2010). The questionnaire was individually filled out after the explanation of the answering procedure of its items.

I-OBE. Following the montage of a 32-channel cap (see details in the EEG recording and analysis section), a 2 min EEG baseline with closed eyes was recorded, at the end of which each participant was reminded that a good level of imagination was an important requisite for this task. This information was delivered to prevent the so-called "hold-back" effect, leading to participants deeming the H-OBE condition as the privileged one and hence restraining from fully applying their cognitive capacities in the I-OBE condition. Then, the participants were asked to imagine having an OBE with the following instructions: "Close your eyes and relax... Now you can start to exit from your body form the top of your head... and now you can reach the ceiling of this room and see your body from there... Now you can move around, wherever you like and without constraints... and enjoy the experience of the lack of gravity... and the capacity of moving and rolling like an astronaut in orbit... You may even trespass walls without any resistance and look at what you want. Pay attention to your emotions and sensations because you will be interviewed about them". After 4 minutes, when still in the I-OBE condition, they were interviewed about their experience using an adaptation of the Greyson Near-Death Experience Scale (Greyson, 1983), available in the Appendix. Then, at the end of the session, they were requested to fill out the PCI.

H-OBE. Hynosis was induced starting with the eye-roll (the same procedure used for HIP administration) followed by verbal suggestions with cues of relax and well-being. Through the voice of an expert hypnotist (E.F or E.C.), each participant was guided towards focusing his/her attention on a single idea, excluding any other external or internal stimuli. The participants were invited to concentrate on their own body from head to foot, whilst a feeling of muscular relaxation was being suggested. Verification of hypnosis was based on some signals, such as the easing of facial tension, eyelid flickering, dropped lower jaw with a slight opening of the mouth, and slowing down of breathing rate.

Then hypnotic suggestions of OBE were delivered with the same instructions used for I-OBE. After 4 minutes, when still in the H-OBE, they were interviewed about their experience using the same adapted version of the Greyson Near-Death Experience Scale used in I-OBE. Then, following deinduction of hypnosis, they were requested to fill out the PCI.

\section{EEG recording and analysis}


The EEG activity was continuously recorded from baseline (2 min closed-eyes, resting condition) through both the I-OBE and H-OBE with a Micromed SD MRI 64 system (Micromed/Treviso, Italy), amplified and digitized with sampling frequency of $512 \mathrm{~Hz}$. A 32-channel Electro-Cap International montage was employed, in accordance with 10-20 international system referenced to the bilateral linked mastoids, using $\mathrm{Ag} / \mathrm{AgCl}$ electrodes. All electrode impedances were kept below $10 \mathrm{~K} \Omega$. Horizontal eye movements were recorded by two electrodes placed at the outer canthus of each eye. All EEG recordings were processed offline using the MATLAB toolbox EEGLAB (Delorme \& Makeig, 2004) and the Brainstorm software (Tadel, Baillet, Mosher, Pantazis, \& Leahy, 2011).

The data were first band-pass filtered between 0.1 and $45 \mathrm{~Hz}$ and then visually inspected to interpolate bad channels. Bad channels-free data were then processed with the Independent Component Analysis (ICA) (Stone \& Stone, 2002). The main purpose of ICA in this case was not to correct eye blinks or saccades, given that participants performed the experimental procedure with closed eyes, but to identify and correct artefacts like muscle contractions, usually easily identifiable by ICA in the electrodes placed around the temples,

The Welch's Power Spectrum Density (PSD) and the imaginary coherence were estimated by using the routines implemented in the Brainstorm software (Tadel et al., 2011). The Welch's PSD, computed for each electrode, were obtained splitting the signals in overlapping windows calculating the Fourier transform (FFT) of each of these epochs, and averaging the power of the FFT coefficients for all the overlapping windows. Coherence (Coh) was calculated at the level of the sensor space. Sensor level coherence may be biased by the volume conduction, leading to the activity of a single generator being recorded by different derivations and electrodes close to each other presenting a high level of coherence. This reflects a volume conduction artefact of a same brain source recorded by different channels instead of a reflection of an underlying interacting brain (Nunez et al., 1997). A possible solution is to reconstruct the brain source, solving the forward and the inverse problem, and then calculate the coherence at the source level instead that at the sensor level, as suggested by Baillet et al. (2001). Although this solution from a methodological point of view is the most accurate, our experimental apparatus does not present all the requirements for a reliable source reconstruction. In fact, as showed by Lantz et al. (2003), the algorithm brain source identification capacity - e,g, in the case of epileptic foci of epileptic spikes - increase with the number of sensors, supporting the insufficiency of 30 electrodes EEG-cup for an accurate localization. Furthermore, in order to generate a more precise source reconstruction, the structural MRI of each participant is necessary in order to 
create an individualized forward model and then solve the inverse model for each participant (Michel and Murray, 2012). Considering the limitation of the present experimental apparatus - i.e., 32 channel EEG-cup and no MRI - a source reconstruction and connectivity might conduct to inaccurate results, misguiding the interpretation of results.

A more affordable way to ford the volume conduction problems, at the sensor-space level, has been proposed by Nolte et al. (2004) and defined as Imaginary Coherence (iCoh). The assumption behind the iCoh it is basically the concept of quasi-static approximation of EEG: it means that the observed scalp potential has no time-lag to the underlying source activity (Stinstra and Peters, 1998) and "If volume conduction does not cause a time-lag, the imaginary part of coherency is hence insensitive to artifactual 'self-interaction" (Nolte et al., 2004). Therefore, taking into account the used 32 EEG channel cup, coherence was computed at the sensor-space level, using the $\mathrm{iCOH}$.

Definition of Coherence. Coherency between two EEG channels, is a cross-correlation of the two at a specific frequency. Let $x(f)$ and $y(f)$ be the (complex) Fourier transforms of the time series $x(t)$ and $y(t)$ and of channel $x$ and $y$ respectively. Then the cross-spectrum is defined as:

$$
G_{x y}(f) \equiv\left\langle x(f) y^{*}(f)\right\rangle
$$

Where * means the complex conjugate, \langle\rangle means the expectation value.

Coherency is basically a measure of how the phases of the signals at the channel $x$ and $y$ are correlated, and it is defined as the normalized cross-spectrum:

$$
C_{x y} \equiv G_{x y}(f) /\left(G_{x x}(f) G_{y y}(f)\right)^{1 / 2}
$$

Coherence is defined as the absolute value of coherency

$$
\operatorname{Coh}_{x y}(f) \equiv\left|C_{x y}(f)\right|
$$

Imagniary Coherence is then calculated as:

$$
i \operatorname{Coh}_{x y}=\operatorname{imag}\left(\operatorname{Coh}_{x y}\right)^{2} /\left(1-\operatorname{real}(\operatorname{Coh})^{2}\right)
$$

iCoh was calculated for each pair of electrodes for each participant, with a maximum frequency resolution of $2 \mathrm{~Hz}$ along the continuous frequency spectrum, and then grouped in 5 frequency bands that represents the mean of the indicated frequency interval: Delta (2-4Hz), Theta (5-7), Alpha (812), Beta (15-29), Gamma (30-45)

(http://it.mathworks.com/help/signal/ref/pwelch.html?requestedDomain=www.mathworks.com). The algorithm of the iCoh, which was calculated at the level of the channel space, allowed to partial out the effect of volume conduction on electrode activity. In fact, when activity of a single generator 
is recorded in different derivations it may result in their strong correlation, due to volume conduction artefact rather than an underlying interaction in the brain (Nunez et al., 1997). This artifact, which has no time-lag to the underlying source activity (Stinstra \& Peters, 1998), can be filtered out by the iCoh - i.e., reconstructing the brain source, calculating the coherence at the source level and solving bot the forward and inverse problems (Baillet et al.,2001).

Then, the difference between OBEs and baseline of the PSD and the imaginary coherence (iCoh;

Nolte et al., 2004) were calculated for each participant.

\section{Statistical analysis}

All inferential analyses were preregistered as monodirectional because higher scores were expected in the "Altered Experience", "Positive Affective", "Self-awareness", "Rationality" and "Memory" subdimensions of the PCI.

The free responses to the adapted Greyson Near-Death-Scale were analysed by a content analysis (Vaismoradi, Turunen, \& Bondas, 2013).

\section{Results}

The scores of both DES and CAPS were below the clinical cut-off in all cases. The DES scores ranged from 4.64 to 27.5 (according to the authors of the tests, a score above 30 can be used as the basis for a clinical interview). In the CAPS, the number of "Yes" responses ranged from 3 to 17 (the range of non-clinical scores ranges from 0 to 26 ).

Two subjects did not return the PCI, one belonging to the I-OBE and the other one to the H-OBE session, while the EEG of one participant was excluded from the analyses due to the presence of too many artifacts. Therefore, the PCI data are based on 13 participants (the raw data are available at https://figshare.com/account/articles/5350135) and those of EEG on 14 participants.

A marked difference between I-OBE and the H-OBE conditions was observed in the following four sub-dimensions of PCI ( see Figure 1). 


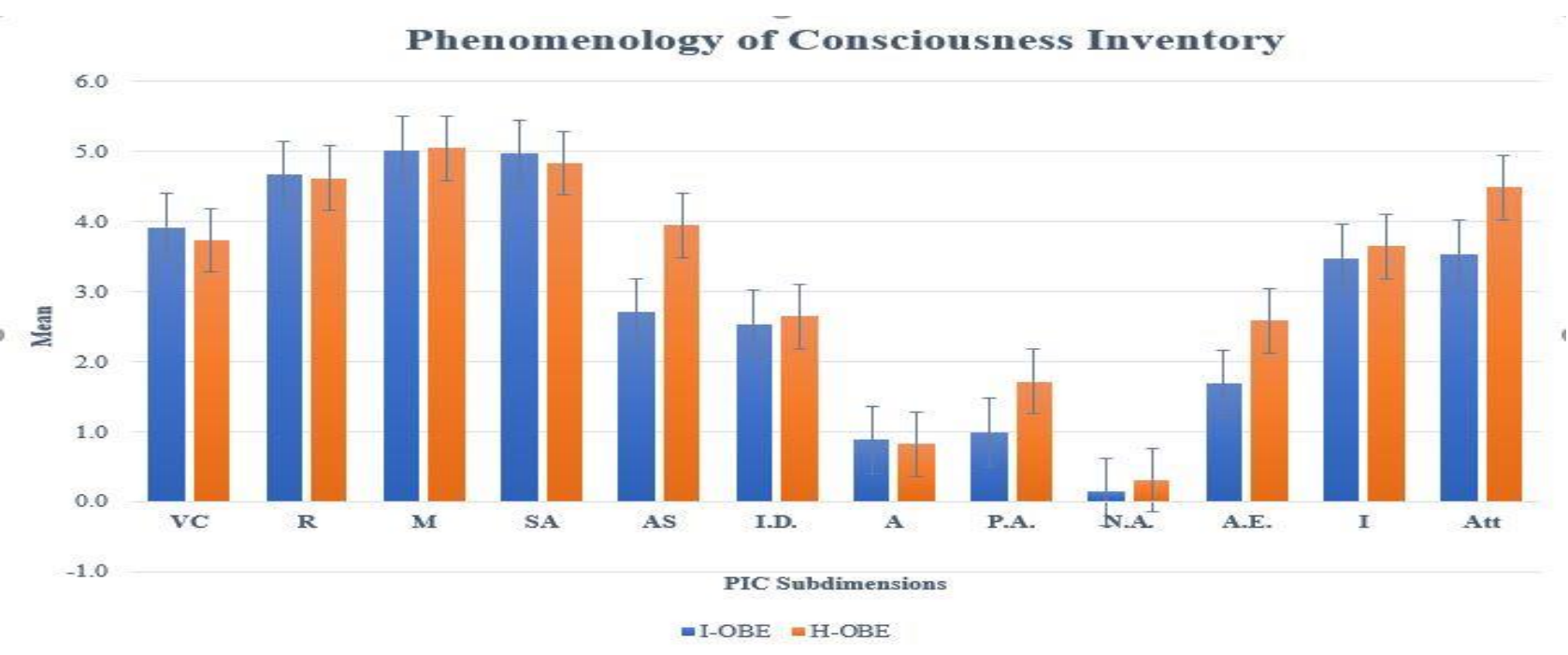

Figure 1: Mean values with corresponding standard deviations of the twelve sub-dimensions of the $\mathrm{PIC}$ in the $\mathrm{I}-\mathrm{OBE}$ and $\mathrm{H}-\mathrm{OBE}$ conditions $(\mathrm{VC}=$ Voluntary Control; $\mathrm{R}=$ Rationality; $\mathrm{M}=\mathrm{Memory}$; $\mathrm{SA}=$ Self-awareness; $\mathrm{AE}=$ Altered Experience; $\mathrm{AS}=$ Altered state of awareness; $\mathrm{ID}=$ Internal dialogue; $\mathrm{A}=$ Arousal; $\mathrm{PA}=$ Positive Affective; NA= Negative Affective; $\mathrm{I}=$ Imagery; Att= Attention).

1) AS-Altered State (e.g. "Ifelt in an extremely different and unusual state of consciousness"; "I felt in an extraordinarily unusual and non-ordinary state of awareness");

2) PA-Positive Affect (e.g. "I felt feelings of ecstasy and extreme happiness"; "I felt intense feelings of loving-kindness");

3) AE-Altered Experience (e.g. "I felt my body greatly expanded beyond the boundaries of my skin"; "Time stood still; there was no movement of time at all"; "Objects in the world around me changed in size, shape, or perspective"; "I had an experience which I would label as very religious, spiritual, or transcendental");

4) Att - Attention (e.g. "My attention was completely inner-directed"; "I was able to concentrate quite well and was not distracted').

Quantitatively, the standardised effect size with the corresponding 95\% high density intervals of these differences were the following: Altered State: .7 (.07-1.37); Positive Affect: .69 (.05-1.35); Altered Experience: .58 (-.04-1.21); Attention: .81 (.11-1.5).

Table 1: Percentages of positive responses in the Imagine OBE and $\mathrm{H}-\mathrm{OBE}$ condition.

\begin{tabular}{cccc}
\hline & I-OBE & H-OBE & $p$ \\
\hline Time speed change & 0.40 & 0.53 & 0.48
\end{tabular}




\begin{tabular}{llll} 
Unity with Universe & 0.40 & 0.60 & 0.28 \\
Feel body separate & 0.20 & 0.60 & 0.02 \\
Body without borders & 0.46 & 0.66 & 0.16 \\
\hline
\end{tabular}

The main differences in the responses to the adapted Greyson's Near-Death Experience Scale regarded the following four questions:

a) "Do you feel time flowing more slowly or quickly than normal?" (e.g. "I had the feeling of lack of time"; "On earth time is longer, while for me only a few seconds pass");

b) "Do you sense harmony or unity with the universe?" (e.g. "I'm flying, I feel in harmony with the universe");

c) "Do you feel separated from your body?" (e.g. "I have a third eye .... The part that is separate is a soul. I feel separated from my body")

d) "In this state of consciousness, do you perceive yourself with borders as in your physical body?" (e.g. "There is no body, there is no boundary"; "I was like water, I did not feel bounded").

The scores of these four responses were higher in H-OBE than in I-OBE, with the feeling of being separated from the body being statistically significant (Table 1).

A significant decreased power in the beta and gamma bands was found in the right hemisphere from baseline to H-OBE condition (see Figure 2).

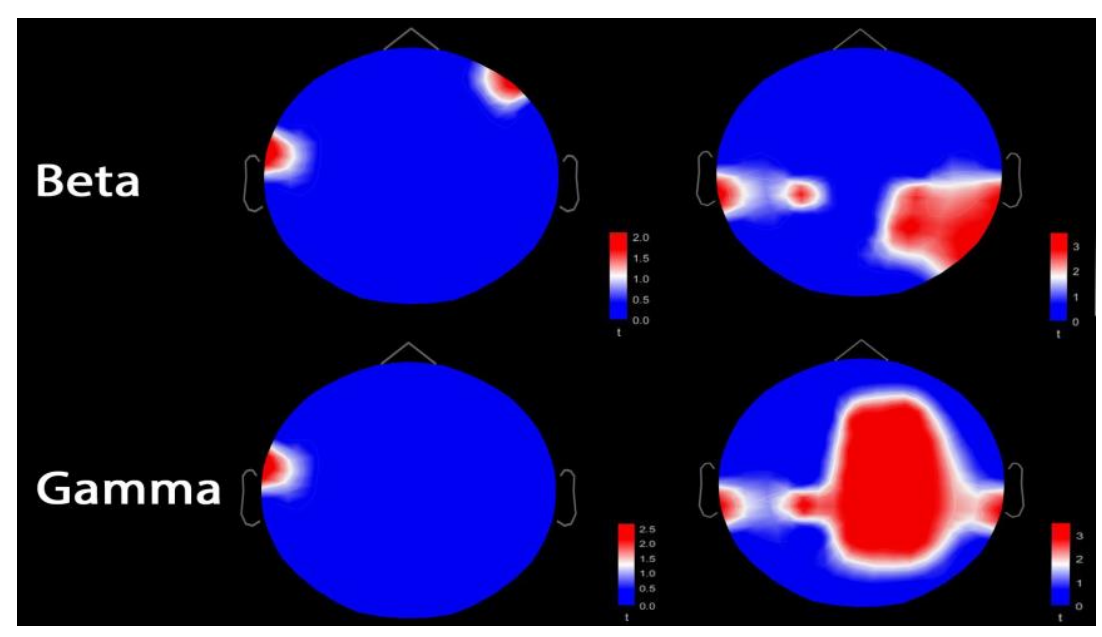

Fig. 2: EEG probability maps in H-OBE and I-OBE: differences in beta and gamma band activities between OBE condition and baseline recording. A significant reduction of power spectrum density in right fronto-parieto-temporal areas is present in $\mathrm{H}-\mathrm{OBE}$ only.

The H-OBE EEG changes were mainly located in the right parieto-temporal areas and spread to the frontal areas in the gamma band. A significant power decrease of the same frequency bands was 
found in the I-OBE condition as well, but was mainly confined to the left temporal derivations. No significant power spectra differences were found when the H-OBE was contrasted with I-OBE and no significant changes of the iCoh were found in any frequency band between the H-OBE and IOBE conditions. In the H-OBE group, 8 out of 14 subjects answered "Yes" to the question: "Do you feel separated from your body?" in the Greyson questionnaire. Despite the very small number of cases, the EEG of these 8 subjects disclosed a further significant decrease in the beta and gamma band activity, (see Figure 3), while no difference were found in the I-OBE condition.

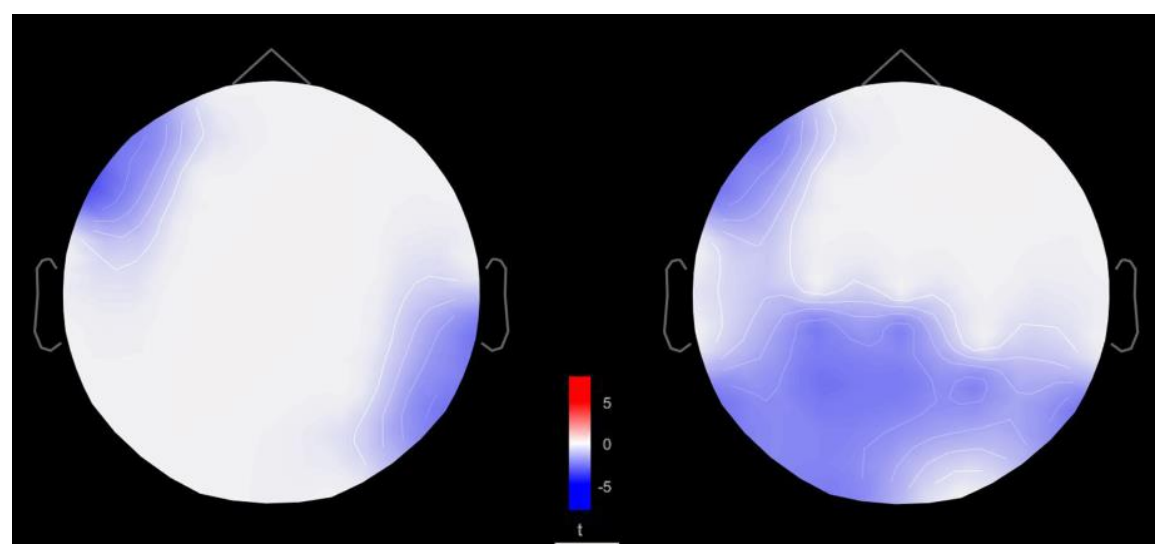

Fig. 3: EEG probability maps in the beta and gamma bands showing the differences between subjects reporting the feeling to be out of their body and the remaining ones in $\mathrm{H}-\mathrm{OBE}$ condition. A significant decrease of power is present in the former.

\section{Discussion}

A wealth of data has been published so far on the neurophysiological markers of hypnosis. The majority of papers compared the EEG activity in High vs. Low-hypnotizable subjects (hereinafter defined as 'Highs' and 'Lows', respectively), in the attempt to seek for an objective classification of hypnotic susceptibility, to check the features of Highs and/or the relationship between EEG, attention shifts and hypnotic tasks. The available data are very heterogeneous due to the variability of the EEG and the wide range of hypnotic tasks and study designs. Thus, discordant or even contradictory results have been sometimes obtained. For example, an increased power in the theta band has been found both in Highs (Cardena et al., 2012; Graffin, Ray \& Lundy, 1995; Sabourin et al., 1990) and in Lows (Williams \& Gruzelier, 2001); likewise, alpha power has been reported to be both related (Williams $\&$ Gruzelier, 2001) and unrelated to hypnotizability (Sabourin et al. 1990).

As far as beta and gamma activities are concerned, a significant correlation with the depth of hypnosis has been reported in Highs (Cardeña et al., 2012, 2013), while gamma band activity and its coherence 
have been related to Highs' ability to recall emotional memories as well (De Pascalis 1989, 1999); furthermore, Jamieson and Burgess (2014) reported a decreased beta-1 imaginary coherence (iCoh) with a focus on fronto-central and posterior hub in Highs compared to Lows.

In the chaotic sea of results reported in the literature, it is hard, if possible to identify single, clearcut, reliable EEG correlates of hypnosis. According to Khilstrom (2013), "Many of these studies were "fishing expeditions", conducted in the hopes that they would yield interesting results, rather than tests of specific hypothesis about the nature or locus of electrocortical changes associated with hypnosis. Still, they were not always without some theoretical rationale, however weak". On the other hand, the neurophysiology of hypnosis is a hard job pervaded by a strong uncertainty, since hypnosis is far from being a single monomorphic activity. As a result, the whole of hypnotic state (defined in terms of relaxation and absorption) and the wide range of possible hypnotic tasks may specifically affect brain activity in different, even opposite ways, and may in turn be affected by different levels of hypnotic ability. For example, opposite changes of auditory Mismatch Negativity during hypnosis have been reported, depending on different hypnotic tasks (Facco et al., 2014; Jamieson et al., 2005; Kallio, Revonsuo, Lauerma, Hamalainen and Lang, 1999)

Indeed, the wide range of possibilities offered by hypnosis makes it an appealing and valuable model to manipulate subjective experience and get an insight on both the physiology and the pathophysiology of the mind-brain functioning, i.e., of its functional and organic disorders. According to Oakley and Halligan (2009), hypnosis is an appealing tool for the following reasons: a) to study consciousness and create clinically informed analogues of functional and structural neuropsychological disorders; b) to check the capacity of mind to intentionally manipulate the activity of unconscious brain areas. The latter is a factor of paramount importance, responsible for relevant clinical results such as hypnotic analgesia (Facco et al., 2011; Facco et al., 2013; Facco, 2016).

The aim of this study was to investigate the neurophenomenological correlates of H-OBEs by comparing them to I-OBEs. Our primary purpose was not the mechanist-reductionist approach, only aimed to check the neuro-correlates of hypnosis; rather, it was to exploit hypnosis in the attempt of better understanding OBE neurophenomenology. Here, the neurophysiological investigations may help joining subjective experience and their neuro-correlates in a whole, as the two inescapable sides of the so-called and still unsolved "hard problem" - a neglected topic by the monist materialist approach, despite its crucial relevance for the understanding of consciousness (Facco \& Fracas, 2018; Facco et al., 2017; Tressoldi et al., 2017). 
It has been hypothesized that OBEs may depend on an altered multisensory integration at the level of right temporo-parietal junction, impairing both vestibular and somatosensory (proprioceptive) information processing (Blanke et al., 2004; Blanke et al., 2005; Lopez et al., 2008) and, thus, yielding autoscopic hallucinations. On the other hand, despite spontaneous OBEs occurring during NDE may resemble autoscopies at a first glance, they differ from autoscopies in many respects (e.g., the localization of the consciousness is clearly perceived as out of the real body) and have been included in the classification of autoscopies as a distinct form (Brugger et al., 1997).

OBEs in non-clinical population have been linked with impaired fronto-parietal attentional networks, which may depend on several factors, including personality features, the proneness to synesthesia and other factors, such as the use of cannabis (Easton, Blanke, \& Mohr, 2009; Terhune, 2009). In this regard, it is worth recalling that the right parietal cortex is involved in the integration of multisensory information (Kanayama, Sato, \& Ohira, 2007, 2009), an activity entailed in both OBEs and synaesthesia - the latter engendering a sensory-visual cross-modal processing.

Gamma-band synchronization is a fundamental operation mode of activated cortical networks, which is essential for cortical computation (Fries, 2009). It also seems to be related to motor preparation and execution as well as multisensory integration; here, beta and gamma bands may be both involved in different steps of processing as well as in aberrant multisensory perception of schizophrenics (Balz et al., 2016; Moisa, Polania, Grueschow, \& Ruff, 2016; Senkowski, Molholm, Gomez-Ramirez, \& Foxe, 2005). If this is the case, OBEs and their related changes of multisensory integration might be reflected by changes of beta and gamma synchronization, where a decreased power might be related to a parallel decrease of crossmodal integration and motor inhibition. Indeed, a study on rubber hand illusion has reported and increased synchronization of gamma band activity following congruent but not incongruent stimulation, reflecting both top-down and bottom-up processing (Kanayama et al., 2007). The authors concluded that their results did not support the hypothesis of an inhibition of multimodal processing as the cause of OBEs and suggested an increased gamma band synchrony (only following spatially congruent multimodal stimulation). On the other hand, the rubber hand illusion is far from being comparable to OBEs as described in NDEs and those elicited in our study. Here, the change of 1PP and the feeling of separation from the physical body might arguably be related to the decreased beta and gamma band activities as a result of crossmodal sensory lack of integration.

A further aspect of our study is the comparison of H-OBE to I-OBE, which may help understanding whether they may yield both qualitatively and quantitatively different kind of experiences. Smith and 
Messier (Smith \& Messier, 2014) have reported on an uncommon case able to elicit OBEs at will without hypnosis, where the fMRI showed activations mainly confined to the left hemisphere, involving the supplementary motor area and supramarginal and posterior superior temporal gyri, a fact interpreted by the authors as expression of kinetic imagery. This imagined OBE seems totally different from the above-mentioned available data on OBE illusions, the main neurophysiological markers of which are located in the right hemisphere, especially the temporo-parietal junction (the neurocorrelates of OBEs and autoscopies are summarized in Figure 4 (see Lopez, Halje, \& Blanke, 2008 , for further details).

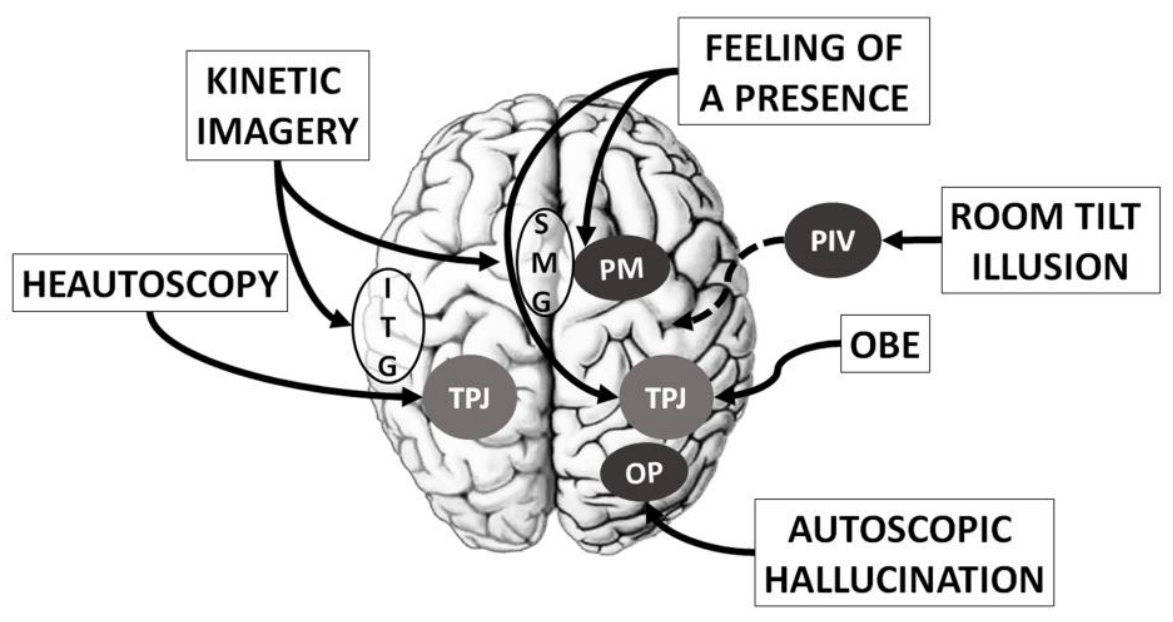

Fig. 4: Schematic representation of the main areas involved in OBEs and other autoscopies [data drawn from Lopez, C., Halje, P., \& Blanke, O. (2008) and Smith, A. M., \& Messier, C. (2014)]

Our results show both quantitative and qualitative subjective differences between the H-OBE and IOBE condition, despite being obtained with exactly the same instructions in the same subjects and, thus, showing the specific role of hyhpnosis as the cause of their features. Quantitative changes were observed in the PCI, while qualitative ones include differences in the perception of the time flow, in the feeling of being separate from the physical body with fading borders and in feeling a sense of unity with the universe, the first of which was statistically significant. Despite this these findings do not allow us to state that the H-OBEs are the same as spontaneous OBEs - i.e., those occurring in NDEs, NDE-like experiences or, anyway unpredictably, in non-clinical subjects - our data support at least a partial overlapping of these two kinds of OBEs for the following reasons:

a) Both H-OBEs and I-OBEs are not illusions yielded by sensory and vestibular stimulation, but depend on an intentional, introspective mental process, where hypnosis yields different and more 
meaningful results with respect to I-OBE including significantly higher scores in the Altered State, Altered Experience, Positive Affect and Attention Subdimensions of the PCI.

b) 9 out of 15 participants (60\%) in H-OBE $v s$. only 3 (20\%) in the I-OBE condition reported to feel themselves as being clearly separated from their body $(p=0.02)$; this also is in line with the higher rate of sense of harmony or unity with the universe and the perception of fading borders of the physical body, all features well described in OBEs during NDEs.

It is worth emphasizing that in the first interview the subjects declared to be neither informed about OBE phenomenology nor have been previously trained in the induction of OBEs. Therefore, they experienced the H-OBE for the first time, with two possible implications: a) the H-OBE might result to be deeper and provide better results following a specific training; b) their novelty might have engendered some uncertainty or misgiving when actually facing the separation from one's own physical body, decreasing their intensity. Such an event clearly occurred in a subject, who reported she had remained halfway between feeling fully embodied and separated from her physical body. On the other hand, we purposefully avoided any training in order to check the differences between $\mathrm{H}$ $\mathrm{OBE}$ and I-OBE in the least condition, which is closer to spontaneously occurring, unpredictable OBEs; further study on $\mathrm{H}-\mathrm{OBE}$ in well trained subjects may provide a further insight on the maximal intensity of the experiences intentionally elicited in hypnosis.

Our EEG data, i.e. the decreased power in the beta and gamma bands in right parieto-temporal regions, agrees with the key role that the temporo-parietal junction (TPJ) seems to play in OBEs (Lenggenhager et al. 2006; Lopez, C., Halje, P., \& Blanke, O., 2008). Despite no data are available on spontaneous OBEs (and, perhaps, they will never be available), it is reasonable arguing that they may share similar neurocorrelates. If this is the case, our results suggests that H-OBEs, with their neurophenomenological changes, may be a good model of spontaneous OBE, or be anyway closer to them than I-OBE or those obtained by sensory and vestibular illusions.

Despite the significant EEG changes from baseline to H-OBEs condition, we did not find significant differences between $\mathrm{H}-\mathrm{OBE}$ and I-OBE, a fact depending on two possible factors: a) the small sample enrolled in this study with respect to the observed effect size, which was approximately .30, as well as the intrinsic variability of EEG signals; b) the possibility of a partial overlapping in the mechanisms of H-OBE and I-OBE - i.e., the intentional introspective imaginative activity - where H-OBEs might yield stronger EEG changes in the right hemisphere. Further study is required to check this provisional interpretation and better define the neurocorrelates of both I-OBEs and H-OBEs. 
OBEs are a still ill-known, ostensibly odd, non-pathological phenomenon sharing some common phenomenological features with other NOMEs, such as those engendered by meditation and mystic experiences (Facco, 2012, 2017, 2018; Facco et al., 2015), unintentionally triggered by injuries (i.e., NDEs), psychological stress (NDE-like Experiences; Facco \& Agrillo, 2012a) or spontaneously occurring in non-clinical population. Therefore, a method able to induce them may allow for a better insight in this intriguing phenomenon.

Some partial OBE-like elements have been induced by vestibular stimulations, own-body transformation tasks or spontaneously occurring in microgravity conditions and in room tilt illusion (Lopez et al. 2008). Nevertheless, room tilt illusion and inversion illusion in microgravity mainly yield a reversal of the visual field (e.g., upside-down reversal) without the experience of separating consciousness from one's body, while galvanic or caloric vestibular stimulation seem to yield partial dissociation between body and self and symptoms of depersonalization and realization at best. In this regard, it is worth stressing that in OBEs occurring during a NDE consciousness is reported to be perfectly clear or even brighter than normal, just the opposite of depersonalization and derealization. Unlike the above-mentioned illusions, in H-OBE the subjects have clearly reported to have left their body on the chair and floated close to the roof of the room, with their consciousness being located there, i.e., showing several phenomenological features of spontaneous OBEs. Furthermore, H-OBE were associated to EEG changes compatible with a complex task altering the crossmodal sensory integration in the right hemisphere, according to their neurophysiological interpretation.

A keypoint of the phenomenology of OBEs remains their meaning, which does not imply that consciousness actually leaves the body. OBEs have been mainly interpreted in terms of dysfunction and disruption of multisensory integration by the ruling mechanistic approach. On the other hand, HOBE depend on an introspective activity intentionally performed by the subject, a fact hardly compatible with the idea of neurological dysfunction. Likewise, synesthesias were considered in the past decades as a deficit of separation of perceptual modalities due to a developmental failure, brain lesions or the use of hallucinogens; instead, they may depend on a higher-than-normal brain connectivity related to better-than-normal activity, such as creativity (Chun \& Hupe, 2016; Grossenbacher \& Lovelace, 2001; Mroczko-Wasowicz \& Werning, 2012; Safran \& Sanda, 2015). Despite OBEs, as well as NOMEs, may look odd from an unyielding physicalist perspective (the limits and pitfalls of which have been discussed in detail elsewhere; see Facco \& Fracas, 2018; Facco et al., 2017), they may be endowed with a relevant cognitive and metacognitive potential, leading to resilience being enhanced and the fear of death being overcome. If this is the case, they may reveal 
unexpected relevant therapeutic implications. In this regard, it is worth mentioning the meditation on one's own death in supine position (especially used in Tantric and Tibetan Buddhism) allows for experiences similar to NDEs, including the life review, and the understanding of the meaning of life (Facco, 2014; Van Gordon et al., 2018). Furhtermore, there is a meaningful link between hypnosis and meditation (Facco, 2014, 2017), as well as between NDEs and hypnosis (E. Facco, 2012, 2018), while NDE-like experiences permissively suggested in hypnosis might help improving second order changes and resilience (Schenk, 1999).

The same might be for other NOMEs such as NDEs and OBEs, besides hypnosis and meditation, given their transformational power. In fact, their ostensible peculiarity with respect to ordinary features of consciousness and experience is conventional in nature, depending on statistical criteria of normality and on the adopted metaphysicis (i.e., accepted axioms and theories) at a given time; they do not imply a priori any dysfunction but only their diversity with the adopted Weltanshaaung (the view of the world) and Zeitgeist (the spirit of times), suggesting the need for shifting their interpretation from the only field of physical disorders to their epistemological implications (as emphasized by the very concept of NOMEs). The link between hypnosis, meditation and other NOMEs - such as mysticial experiences, NDEs, OBEs and synesthesias -also involves art, poetry, music and science itself, as well as psychiatric disorders (Facco, 2012, 2018, E. Facco \& Agrillo, 2012a, 2012b). Their meaning looks hardly understandable by a reductive physicalist approach focused on brain circuitry only and unable to properly tell non-pathological or even better-thannormal NOMEs from psychiatric disorders, a problem already well defined by Plato in the Phaedrus (265a) as follows: "[Socrates] And of madness there were two kinds; one produced by human infirmity, the other was a divine release of the soul from the yoke of custom and convention". Plato's statement wisely emphasizes the epistemological implications of NOMEs and points out the neeed to properly understand them, avoding simple judgments based on custom and conventions and/or restricted to the axioms of reductive physicalism: without this divine release no cultural progress would be possible, not even Einstein's great intuitions on relativity and the revolution of classic thought introduced by quantum physics, well meeting the Kuhn's concept of scientific revolutions (Kuhn, 1962).

\section{Conclusions and Future Studies}

Our data suggest that H-OBEs may be a useful experimental model of at least some aspects of spontaneous OBEs, as shown by the whole of their phenomenological and neurophysiological features. The lack of significant EEG differences between I-OBE and H-OBE may depend on the 
small sample size, EEG variability as well as the fact that H-OBE and I-OBE might partly depend on common mechanisms - i.e., intentional imagination, where hypnosis may allow for much deeper experiences. Further study is required to define the similarities and differences between them.

Our study is based on a limited sample and its results should not be overestimated; the findings are to be considered as hints rather than facts, to be confirmed by further studies on larger samples able to provide more accurate and statistically reliable results. They would allow to better check the neurophenomenological aspects of H-OBEs and their specific features with respect to the same imaginary task without hypnosis (I-OBEs). Further studies should also compare Highs to MediumLows and, within Highs, check the correlation between EEG changes and the intensity of the experience of feeling out-of-body, where a specific training in H-OBEs might probably provide stronger effects. Furthermore, EEG montages with higher electrode spatial frequency (e.g., a 64 or 128 channel montage) might strongly improve the localization of EEG changes yielded by H-OBEs and allow for their source analysis.

Despite all the above-mentioned limitations, our results show that OBEs can be easily inducible in hypnosis and that their features are at least partially different from those yielded by the same imaginary task performed without hypnosis. This is in line with the above-mentioned concept of experimental hypnosis as a valuable model to manipulate subjective experience and get an insight on mind-brain physiology and pathophysiology. The observed EEG changes in H-OBEs are also in line with the available neuropsychological data on the mechanisms of OBEs illusions and autoscopies. The intensity of subjects' experience, as defined by PCI and the Greyson modified scale, suggests an intriguing link between feeling out of one's body and positive emotions, a still poorly understood phenomenon common to NDEs and other NOMEs. Despite looking odd, this phenomenological aspect is of paramount importance to properly understand the meaning of these experiences, given their metacognitive and transformational potential, which, once understood, might also disclose possible unforeseen therapeutical implications. 


\section{References}

Agrillo, C. (2011). Near-death experience: Out-of-body and out-of-brain? Review of General Psychology, 15(1), 1-10. https://doi.org/10.1037/a0021992

Altschuler, E. L., \& Ramachandran, V. S. (2007). A simple method to stand outside oneself. Perception, 36(4), 632-634.

Baillet, S., Riera, J. J., Marin, G., Mangin, J. F., Aubert, J., \& Garnero, L. (2001). Evaluation of inverse methods and head models for EEG source localization using a human skull phantom. Physics in Medicine and Biology, 46(1), 77-96. http://www.ncbi.nlm.nih.gov/pubmed/11197680

Balz, J., Roa Romero, Y., Keil, J., Krebber, M., Niedeggen, M., Gallinat, J., \& Senkowski, D. (2016). Beta/Gamma Oscillations and Event-Related Potentials Indicate Aberrant Multisensory Processing in Schizophrenia. Frontiers in Psychology, 7, 1896. https://doi.org/10.3389/fpsyg.2016.01896

Bell, V., Halligan, P. W., \& Ellis, H. D. (2006). The Cardiff Anomalous Perceptions Scale (CAPS): A New Validated Measure of Anomalous Perceptual Experience. Schizophrenia Bulletin, 32(2), 366-377. https://doi.org/10.1093/schbul/sbj014

Blanke, O., Landis, T., Spinelli, L., \& Seeck, M. (2004). Out-of-body experience and autoscopy of neurological origin. Brain, 127(2), 243-258. https://doi.org/10.1093/brain/awh040

Blanke, O., \& Metzinger, T. (2009). Full-body illusions and minimal phenomenal selfhood. Trends in Cognitive Sciences, 13(1), 7-13. https://doi.org/10.1016/j.tics.2008.10.003

Bourdin, P., Barberia, I., Oliva, R., Slater, M., Parnia, S., Waller, D., ... Alvarado, C. (2017). A Virtual Out-of-Body Experience Reduces Fear of Death. PLOS ONE, 12(1), e0169343. https://doi.org/10.1371/journal.pone.0169343

Braithwaite, J. J., Samson, D., Apperly, I., Broglia, E., \& Hulleman, J. (2011). Cognitive correlates of the spontaneous out-of-body experience (OBE) in the psychologically normal population: Evidence for an increased role of temporal-lobe instability, body-distortion processing, and impairments in own-body transformations. Cortex, 47(7), 839-853. https://doi.org/10.1016/j.cortex.2010.05.002

Brewer, J. A., Worhunsky, P. D., Gray, J. R., Tang, Y. Y., Weber, J., \& Kober, H. (2011). Meditation experience is associated with differences in default mode network activity and connectivity. Proceedings of the National Academy of Sciences U.S.A, 108(50), 20254-20259.

Britton, W. B., \& Bootzin, R. R. (2004). Near-Death Experiences and the Temporal Lobe. Psychological Science, 15(4), 254-258. https://doi.org/10.1111/j.0956-7976.2004.00661.x

Brugger, P., Regard, M., \& Landis, T. (1997). Illusory Reduplication of One's Own Body: Phenomenology and Classification of Autoscopic Phenomena. Cognitive Neuropsychiatry, 2(1), 19-38. https://doi.org/10.1080/135468097396397

Bünning, S., \& Blanke, O. (2005). The out-of body experience: precipitating factors and neural correlates. Progress in Brain Research, 150, 331-606. https://doi.org/10.1016/S00796123(05)50024-4

Cardeña, E., \& Alvarado, C. S. (2014). Anomalous self and identity experiences. In E. Cardeña, $\underline{S}$. Lynn \& Krippner (Eds.) Varieties of anomalous experience: Examining the scientific evidence (2nd ed., pp. 175-212). Washington, DC: APA. https://doi.org/10.1037/14258-007

Cardeña, E., \& Facco, E. (2015) (Eds.).Non-Ordinary Mental Expressions. Lausanne, CH: Frontiers Media SA.

Cardeña, E., Lehmann, D., Faber, P. L., Jonsson, P., Milz, P., Pascual-Marqui, R. D., \& Kochi, K. (2012). EEG sLORETA functional imaging during hypnotic arm levitation and voluntary arm lifting. Internantional Journal of Clinical Experimental Hypnosis, 60(1), 31-53.

Cardeña, E., Jönsson, P., Terhune, D. B., \& Marcusson-Clavertz, D. (2013). The 
neurophenomenology of neutral hypnosis. Cortex, 49(2), 375-385. https://doi.org/10.1016/j.cortex.2012.04.001

Carlson, E. B., \& Putnam, F. W. (1993). An update on the Dissociative Experiences Scale. Dissociation: Progress in the Dissociative Disorders, 6(1), 16-27.

Casiglia, E., Schiff, S., Facco, E., Gabbana, A., Tikhonoff, V., Schiavon, L. et al. (2010). Neurophysiological correlates of post-hypnotic alexia: a controlled study with Stroop test. American Journal of Clinical Hypnosis, 52(3), 219-233.

Charland-Verville, V., Jourdan, J.-P., Thonnard, M., Ledoux, D., Donneau, A.-F., Quertemont, E., \& Laureys, S. (2014). Near-death experiences in non-life-threatening events and coma of different etiologies. Frontiers in Human Neuroscience, 8, 203. https://doi.org/10.3389/fnhum.2014.00203

Chen, Z., Qi, W., Hood Jr, R. W., \& Watson, P. J. (2011). Core Thesis and Qualitative and Quantitative Analysis of Mysticism in Chinese Buddhist Monks and Nuns. Journal for the Scientific Study of Religion, 50, 654-670.

Chun, C. A., \& Hupe, J. M. (2016). Are synesthetes exceptional beyond their synesthetic associations? A systematic comparison of creativity, personality, cognition, and mental imagery in synesthetes and controls. British Journal of Psychology, 107, 397-418.

De Foe, A., Al Khafaji, B. E., Pederzoli, L., Prati, E., \& Tressoldi, P. E. (2017). Out-of-BodyExperiences: A Phenomenological Comparison of Different Causes. SSRN: https://ssrn.com/abstract=2903827 or http://dx.doi.org/10.2139/ssrn.2903827

De Pascalis, V., Marucci, F. S., \& Penna, P. M. (1989). 40-Hz EEG asymmetry during recall of emotional events in waking and hypnosis: differences between low and high hypnotizables. International Journal of Psychophysiology, 7, 85-96.

De Pascalis, V. (1999). Psychophysiological correlates of hypnosis and hypnotic susceptibility. International Journal of Clinical and Experimental Hypnosis, 47, 117-143.

Deeley, Q., Oakley, D. A., Toone, B., Giampietro, V., Brammer, M. J., Williams, S. C. et al. (2012). Modulating the default mode network using hypnosis. International Journal of Clinical and Experimental Hypnosis, International Journal of Clinical and Experimental Hypnosis, 60(2), 206-228. doi:10.1080/00207144.2012.648070 [doi].

Delorme, A., \& Makeig, S. (2004). EEGLAB: An open source toolbox for analysis of single-trial EEG dynamics including independent component analysis. Journal of Neuroscience Methods, 134(1), 9-21. https://doi.org/10.1016/j.jneumeth.2003.10.009

Derbyshire, S. W., Whalley, M. G., Stenger, V. A., \& Oakley, D. A. (2004). Cerebral activation during hypnotically induced and imagined pain. Neuroimage, 23(1), 392-401. doi:10.1016/j.neuroimage.2004.04.033 [doi];S1053811904002435 [pii].

Easton, S., Blanke, O., \& Mohr, C. (2009). A putative implication for fronto-parietal connectivity in out-of-body experiences. Cortex, 45(2), 216-227.

Egner, T., Jamieson, G., \& Gruzelier, J. (2005). Hypnosis decouples cognitive control from conflict monitoring processes of the frontal lobe. Neuroimage, 27(4), 969-978. doi:S10538119(05)00317-4 [pii];10.1016/j.neuroimage.2005.05.002 [doi].

Facco, E. (2012). Near-death experiences and hypnosis: Two diferent phenomena with something in common. Contemporary Hypnosis and Integrative Therapy, 29(3), 284-297.

Facco, E. (2014). Meditazione e Ipnosi tra neuroscienze, filosofia e pregiudizio. Lungavilla, PV, Italy: Altravista.

Facco, E. (2016). Hypnosis and anesthesia: back to the future. Minerva Anestesiologica, 82(12), 1343-1356. doi:R02Y9999N00A16083001 [pii].

Facco, E. (2017). Meditation and Hypnosis: Two Sides of the Same Coin? International Journal of Clinical and Experimental Hypnosis, 65(2). https://doi.org/10.1080/00207144.2017.1276361 
Facco, E. (2018). Ipnosi ed Esperienze di Premorte nel continuum delle Espressioni Non Ordinarie della Mente. Ipnosi, 1, 13-38. https://doi.org/10.3280/IPN2018-001002

Facco, E., \& Agrillo, C. (2012a). Near-death-like experiences without life-threatening conditions or brain disorders: A hypothesis from a case report. Frontiers in Psychology, 3(art. 490), 1-6. https://doi.org/10.3389/fpsyg.2012.00490

Facco, E., \& Agrillo, C. (2012b). Near-death experiences between science and prejudice. Frontiers in Human Neuroscience, 6 (art. 209), 1-7. https://doi.org/10.3389/fnhum.2012.00209

Facco, E., \& Fracas, F. (2018). L'enigma della coscienza. Milano: Mondadori.

Facco, E., Agrillo, C., \& Greyson, B. (2015). Epistemological implications of near-death experiences and other non-ordinary mental expressions: Moving beyond the concept of altered state of consciousness. Medical Hypotheses, 85(1), 85-93. https://doi.org/10.1016/j.mehy.2015.04.004

Facco, E., Casiglia, E., Masiero, S., Tikhonoff, V., Giacomello, M., \& Zanette, G. (2011). Effects of hypnotic focused analgesia on dental pain threshold. International Journal of Clinical and Experimental Hypnosis, 59(4), 454-468.

Facco, E., Lucangeli, D., \& Tressoldi, P. (2017). On the Science of Consciousness: Epistemological Reflections and Clinical Implications. Explore: The Journal of Science and Healing, 13(3), 163180. https://doi.org/10.1016/j.explore.2017.02.007

Facco, E., Pasquali, S., Zanette, G., \& Casiglia, E. (2013). Hypnosis as sole anaesthesia for skin tumour removal in a patient with multiple chemical sensitivity. Anaesthesia, 68(9), 961-965. doi:10.1111/anae.12251 [doi].

Facco, E., Ermani, M., Rampazzo, P., Tikhonoff, V., Saladini, M., Zanette, G. et al. (2014). Topdown regulation of left temporal cortex by hypnotic amusia for rhythm: a pilot study on mismatch negativity. International Journal of Clinical and Experimental Hypnosis,, 62(2), 129144. doi:10.1080/00207144.2014.869124 [doi].

Faul, F., Erdfelder, E., Lang, A.-G., \& Buchner, A. (2007). G*Power 3: A flexible statistical power analysis program for the social, behavioral, and biomedical sciences. Behavior Research Methods, 39(2), 175-191. https://doi.org/10.3758/BF03193146.

Faymonville, M. E., Boly, M., \& Laureys, S. (2006). Functional neuroanatomy of the hypnotic state. Journal of Physiology, Paris, 99(4-6), 463-469. doi:S0928-4257(06)00017-9 [pii];10.1016/j.jphysparis.2006.03.018 [doi].

Faymonville, M. E., Laureys, S., Degueldre, C., DelFiore, G., Luxen, A., Franck, G. et al. (2000). Neural mechanisms of antinociceptive effects of hypnosis. Anesthesiology, 92(5), 1257-1267. Retrieved from PM:10781270

Faymonville, M. E., Roediger, L., Del, F. G., Delgueldre, C., Phillips, C., Lamy, M. et al. (2003). Increased cerebral functional connectivity underlying the antinociceptive effects of hypnosis. Brain research. Cognitive brain research, 17(2), 255-262. doi:S0926641003001137 [pii]. Retrieved from PM:12880897

Fries, P. (2009). Neuronal Gamma-Band Synchronization as a Fundamental Process in Cortical Computation. Annual Review of Neuroscience, 32(1), 209-224. https://doi.org/10.1146/annurev.neuro.051508.135603

Frith, C. (2002). Attention to action and awareness of other minds. Conscious Cognition, 11(4), 481-487.

Graffin, N. F., Ray, W. J., \& Lundy, R. (1995). EEG concomitants of hypnosis and hypnotic susceptibility. Journal of Abnormal Psychology, 104(1), 123-31. http://www.ncbi.nlm.nih.gov/pubmed/7897034

Greyson, B. (1983). The near-death experience scale. Construction, reliability, and validity. Journal of Nervous and Mental Diseases, 171(0022-3018), 369-375. 
Greyson, B. (2000). Dissociation in people who have near-death experiences: out of their bodies or out of their minds? Lancet, 355(0140-6736), 460-463.

Greyson, B. (2003). Incidence and correlates of near-death experiences in a cardiac care unit. General Hospital Psychiatry, 25(4), 269-276. https://doi.org/10.1016/S0163-8343(03)00042-2

Greyson, B. (2014). Congruence Between Near-Death and Mystical Experience. The International Journal for the Psychology of Religion, 24(4), 298-310. https://doi.org/10.1080/10508619.2013.845005

Grossenbacher, P. G., \& Lovelace, C. T. (2001). Mechanisms of synesthesia: cognitive and physiological constraints. Trends in Cognitive Science, 5(1), 36-41.

Hofbauer, R. K., Rainville, P., Duncan, G. H., \& Bushnell, M. C. (2001). Cortical representation of the sensory dimension of pain. Journal of Neurophysiology, 86(1), 402-411.

Isotani, T., Tanaka, H., Lehmann, D., Pascual-Marqui, R. D., Kochi, K., Saito, N., ... Sasada, K. (2001). Source localization of EEG activity during hypnotically induced anxiety and relaxation. International Journal of Psychophysiology, 41, 143-153.

Jamieson, G. A., Dwivedi, P., \& Gruzelier, J. H. (2005). Changes in mismatch negativity across pre-hypnosis, hypnosis and post-hypnosis conditions distinguish high from low hypnotic susceptibility groups. Brain Research Bullettin, 67(4), 298-303.

Jamieson, G. A., \& Burgess, A. P. (2014). Hypnotic induction is followed by state-like changes in the organization of EEG functional connectivity in the theta and beta frequency bands in highhypnotically susceptible individuals. Frontiers of Human Neuroscience, 8 (ART. 528), 1-11.

Jang, J. H., Jung, W. H., Kang, D. H., Byun, M. S., Kwon, S. J., Choi, C. H., \& Kwon, J. S. (2011). Increased default mode network connectivity associated with meditation. Neuroscience Letters, 487(3), 358-362.

Jasp Team. (2017). JASP. Version 0.8.2.0 (https://jasp-stats.org/team/).

Kallio, S., Revonsuo, A., Lauerma, H., Hamalainen, H., \& Lang, H. (1999). The MMN amplitude increases in hypnosis: a case study. Neuroreport, 10(17), 3579-3582.

Kanayama, N., Sato, A., \& Ohira, H. (2007). Crossmodal effect with rubber hand illusion and gamma-band activity. Psychophysiology, 44(3), 392-402. https://doi.org/10.1111/j.14698986.2007.00511.x

Kanayama, N., Sato, A., \& Ohira, H. (2009). The role of gamma band oscillations and synchrony on rubber hand illusion and crossmodal integration. Brain and Cognition, 69(1), 19-29. https://doi.org/10.1016/j.bandc.2008.05.001

Kihlstrom, J. F. (2013). Neuro-hypnotism: Prospects for hypnosis and neuroscience. Cortex, 49(2), 365-374. https://doi.org/10.1016/j.cortex.2012.05.016

Kuhn, T. S. (1962). The structure of scientific revolutions. Chicago: University of Chicago Press.

Lantz, G., De Peralta, R. G., Spinelli, L., Seeck, M., \& Michel, C. M. (2003). Epileptic source localization with high density EEG: how many electrodes are needed? Clinical neurophysiology, 114(1), 63-69.

Lenggenhager, B., Smith, S. T., \& Blanke, O. (2006). Functional and neural mechanisms of embodiment: importance of the vestibular system and the temporal parietal junction. Reviews in the Neurosciences, 17(0334-1763 (Print)), 643-657.

London, J. (1915). The Star Rover. New York: McMillan.

Lopez, C., Halje, P., \& Blanke, O. (2008). Body ownership and embodiment: vestibular and multisensory mechanisms. Neurophysiologie Clinique, 38(3) 149-161.

Mak, A. K., Hu, Z. G., Zhang, J. X., Xiao, Z., \& Lee, T. M. (2009). Sex-related differences in neural activity during emotion regulation. Neuropsychologia, 47(13), 2900-2908. doi:S00283932(09)00268-1 [pii];10.1016/j.neuropsychologia.2009.06.017 [doi].

McGeown, W. J., Mazzoni, G., Venneri, A., \& Kirsch, I. (2009). Hypnotic induction decreases 
anterior default mode activity. Consciousness and Cognition, 18(4), 848-855. doi:S10538100(09)00139-1 [pii];10.1016/j.concog.2009.09.001 [doi].

Michel, C. M., \& Murray, M. M. (2012). Towards the utilization of EEG as a brain imaging tool. Neuroimage, 61(2), 371-385.

Moisa, M., Polania, R., Grueschow, M., \& Ruff, C. C. (2016). Brain Network Mechanisms Underlying Motor Enhancement by Transcranial Entrainment of Gamma Oscillations. The Journal of Neuroscience, 36(47), 12053-12065. https://doi.org/10.1523/JNEUROSCI.204416.2016

Mroczko-Wasowicz, A., \& Werning, M. (2012). Synesthesia, sensory-motor contingency, and semantic emulation: how swimming style-color synesthesia challenges the traditional view of synesthesia. Frontiers in Psychology, 3(art. 279), 1-12.

Muller, K., Bacht, K., Prochnow, D., Schramm, S., \& Seitz, R. J. (2012). Activation of thalamus in motor imagery results from gating by hypnosis. Neuroimage, 66C, 361-367.

Nolte, G., Bai, O., Wheaton, L., Mari, Z., Vorbach, S., \& Hallett, M. (2004). Identifying true brain interaction from EEG data using the imaginary part of coherency. Clinical Neurophysiology, 115(10), 2292-2307. https://doi.org/10.1016/j.clinph.2004.04.029

Nunez, P. L., Srinivasan, R., Westdorp, A. F., Wijesinghe, R. S., Tucker, D. M., Silberstein, R. B., \& Cadusch, P. J. (1997). EEG coherency. I: Statistics, reference electrode, volume conduction, Laplacians, cortical imaging, and interpretation at multiple scales. Electroencephalography and Clinical Neurophysiology, 103(5), 499-515.

Oakley, D. A., \& Halligan, P. W. (2009). Hypnotic suggestion and cognitive neuroscience. Trends in Cognitive Sciences, 13(6), 264-270. doi:S1364-6613(09)00092-8 [pii];10.1016/j.tics.2009.03.004 [doi].

Overney, L. S., Arzy, S., \& Blanke, O. (2009). Deficient mental own-body imagery in a neurological patient with out-of-body experiences due to cannabis use. Cortex, 45(2), 228-235.

Pagnoni, G., Cekic, M., \& Guo, Y. (2008). "Thinking about not-thinking”: neural correlates of conceptual processing during Zen meditation. PlosOne, 3(9), e3083.

Parnia, S., Spearpoint, K., de, V. G., Fenwick, P., Goldberg, D., Yang, J., ... Schoenfeld, E. R. (2014). AWARE-Awareness during Resuscitation-A prospective study. Resuscitation, 85(12), 1799-1805.

Pederzoli, L., Giroldini, W., Duma, G. M., Mento, G., Prati, E., \& Tressoldi, P. E. (2016). Out-ofBody Experience Induced by Hypnotic Induction: A Neurophenomenological Study. SSRN (https://ssrn.com/abstract=2820689 or http://dx.doi.org/10.2139/ssrn.2820689).

Pekala, R. J. (2013). Quantifying consciousness: An empirical approach. New York: Springer Science \& Business media.

Pekala, R. J., Kumar, V. K., Maurer, R., Elliott-Carter, N., Moon, E., \& Mullen, K. (2010). Suggestibility, expectancy, trance state effects, and hypnotic depth: I. II. Assessment via the PCIHAP. American Journal of Clinical Hypnosis, 52(4), 291-318.

Rainville, P., Carrier, B., Hofbauer, R. K., Bushnell, M. C., \& Duncan, G. H. (1999a). Dissociation of sensory and affective dimensions of pain using hypnotic modulation. Pain, 82(2), 159-171.

Rainville, P., Hofbauer, R. K., Bushnell, M. C., Duncan, G. H., \& Price, D. D. (2002). Hypnosis modulates activity in brain structures involved in the regulation of consciousness. Journal of cognitive neuroscience, 14(6), 887-901.

Rainville, P., Hofbauer, R. K., Paus, T., Duncan, G. H., Bushnell, M. C., \& Price, D. D. (1999b). Cerebral mechanisms of hypnotic induction and suggestion. Journal of cognitive neurosciences, 11(1), 110-125.

Rainville, P., \& Price, D. D. (2003). Hypnosis phenomenology and the neurobiology of 
consciousness. International Journal of Clinical and Experimental Hypnosis, 51(2), 105-129. doi:10.1076/iceh.51.2.105.14613 [doi].

Raz, A., Fan, J., \& Posner, M. I. (2005). Hypnotic suggestion reduces conflict in the human brain. Proceedings of the National Academy of Sciences U.S.A, 102(28), 9978-9983. doi:0503064102 [pii];10.1073/pnas.0503064102 [doi]

Roder, C. H., Michal, M., Overbeck, G., van de Ven, V., \& Linden, D. E. (2007). Pain response in depersonalization: a functional imaging study using hypnosis in healthy subjects. Psychotherapy and psychosomatics, 76(2), 115-121.

Rodin, E.A. (1989). Comments on "A neurobiological model for near-death experiences". Journal of Near-Death Studies, 7, 255-259.

Sabom, M. B. (1998). Light \& death. USA: Zondervan.

Sabourin, M. E., Cutcomb, S. D., Crawford, H. J., \& Pribram, K. (1990). EEG correlates of hypnotic susceptibility and hypnotic trance: spectral analysis and coherence. International Journal of Psychophysiology, 10(2), 125-42.

Safran, A. B., \& Sanda, N. (2015). Color synesthesia. Insight into perception, emotion, and consciousness. Current Opinions in NEurology, 28(1), 36-44.

Schenk, P. W. (1999). The benefits of working with a "dead" patient: hypnotically facilitated pseudo near-death experiences. American Journal of Clinical Hypnosis, 42(1), 36-49.

Senkowski, D., Molholm, S., Gomez-Ramirez, M., \& Foxe, J. J. (2005). Oscillatory Beta Activity

Predicts Response Speed during a Multisensory Audiovisual Reaction Time Task: A High-Density Electrical Mapping Study. Cerebral Cortex, 16(11), 1556-1565. https://doi.org/10.1093/cercor/bhj091

Smith, A. M., \& Messier, C. (2014). Voluntary Out-of-Body Experience: An fMRI Study. Frontiers in Human Neurosciences, 8(art. 70), 1-10.

Spiegel, H. (1977). The Hypnotic Induction Profile (HIP): A review of its development. Annals of the New York Academy of Sciences, 296(1 Conceptual an), 129-142. https://doi.org/10.1111/j.1749-6632.1977.tb38167.x

Spiegel, H., \& Spiegel, D. (2004). Trance \& Treatment. Arlington (US): American Psychiatric Publishing.

Stinstra, J. G., \& Peters, M. J. (1998). The volume conductor may act as a temporal filter on the ECG and EEG. Medical \& Biological Engineering \& Computing, 36(6), 711-6. (http://www.ncbi.nlm.nih.gov/pubmed/10367461)

Stone, J. V, \& Stone, J. V. (2002). Independent component analysis: an introduction. Trends in Cognitive Sciences, 6(2), 59-64. https://doi.org/10.1016/S1364-6613(00)01813-1

Tadel, F., Baillet, S., Mosher, J. C., Pantazis, D., \& Leahy, R. M. (2011). Brainstorm: A userfriendly application for MEG/EEG analysis. Computational Intelligence and Neuroscience. Art. 879716, 1-13. https://doi.org/10.1155/2011/879716

Taylor, V. A., Daneault, V., Grant, J., Scavone, G., Breton, E., Roffe-Vidal, S., .. Beauregard, M. (2013). Impact of meditation training on the default mode network during a restful state. Social cognitive and affective neuroscience, 8(1), 4-14.

Terhune, D. B. (2009). The incidence and determinants of visual phenomenology during out-ofbody experiences. Cortex, 45(2), 236-242.

Tressoldi, P. E., Pederzoli, L., Caini, P., Ferrini, A., Melloni, S., Prati, E., ... Trabucco, A. (2015). Hypnotically Induced Out-of-Body Experience: How Many Bodies Are There? Unexpected Discoveries About the Subtle Body and Psychic Body. SAGE Open, 5(4), 1-11. https://doi.org/10.1177/2158244015615919

Tressoldi, P. E., Pederzoli, L., Caini, P., Ferrini, A., Melloni, S., Richeldi, D., ... Trabucco, A. 
(2014). Out of Body Experience Induced by Hypnotic Suggestion. Part 1: Phenomenology and Perceptual Characteristics. SSRN. https://doi.org/10.2139/ssrn.2443719

Tressoldi, P., Facco, E., \& Lucangeli, D. (2017). On the primacy and irreducible nature of firstperson versus third-person information. F1000Research, 6(99), 1-26.

doi:10.12688/f1000research.10752.3

Vaismoradi, M., Turunen, H., \& Bondas, T. (2013). Content analysis and thematic analysis: Implications for conducting a qualitative descriptive study. Nursing \& Health Sciences, 15(3), 398-405. https://doi.org/10.1111/nhs.12048

Van Gordon, W., Shonin, E., Dunn, T. J., Sheffield, D., Garcia-Campayo, J., \& Griffiths, M. D. (2018). Meditation-Induced Near-Death Experiences: a 3-Year Longitudinal Study. Mindfulness. https://doi.org/10.1007/s12671-018-0922-3

Van Lommel, P. (2011). Near-death experiences: the experience of the self as real and not as an illusion. Annals of the New York Academy of Sciences, 1234(1), 19-28.

https://doi.org/10.1111/j.1749-6632.2011.06080.x

Vanhaudenhuyse, A., Laureys, S., \& Faymonville, M. E. (2014). Neurophysiology of hypnosis. Neurophysiologie Clinique, 44(4), 343-353.

doi:S0987-7053(13)00197-4 [pii];10.1016/j.neucli.2013.09.006 [doi].

Vincent, J. L., Kahn, I., Snyder, A. Z., Raichle, M. E., \& Buckner, R. L. (2008). Evidence for a frontoparietal control system revealed by intrinsic functional connectivity. Journal of Neurophysiology 100(6), 3328-3342. doi:90355.2008 [pii];10.1152/jn.90355.2008 [doi].

Williams, J. D., \& Gruzelier, J. H. (2001). Differentiation of hypnosis and relaxation by analysis of narrow band theta and alpha frequencies. International Journal of Clinical and Experimental Hypnosis, 49(3), 185-206. https://doi.org/10.1080/00207140108410070 


\section{Appendix}

\section{Interview}

(1) Do you feel time flowing more slowly or quickly than normal?

(2) Do you feel your thoughts accelerate/go faster than normal?

(3) Do you see scenes from your past?

(4) Do you suddenly seem to understand everything?

(5) Do you feel peace or pleasantness?

(6) Do you feel joy?

(7) Do you sense harmony or unity with the universe?

(8) Do you see or feel surrounded by a brilliant light?

(9) Are your senses more vivid than usual?

9a) How can you describe this state of consciousness? Are there differences with respect to a dream?

(10) Are you aware of things going on elsewhere, as if by extrasensory perception?

(11) Do you see scenes from the future?

(12) Do you feel separated from your body?

12a) In this state of consciousness, do you perceive yourself with borders as in your physical body?

(13) Do you feel to be entered in some other, unearthly world?

(14) Do you feel the presence of a mystical being or hear an unidentifiable voice?

(15) Do you see dead people or spiritual beings? 